Article

\title{
A University-Assisted, Place-Based Model for Enhancing Students' Peer, Family, and Community Ecologies
}

\author{
Michael A. Lawson 1,*, Tania Alameda-Lawson ${ }^{2}$ and K. Andrew R. Richards ${ }^{3}$ \\ 1 Department of Educational Studies, College of Education, University of Alabama, Tuscaloosa, \\ AL 35487, USA \\ 2 School of Social Work, University of Alabama, Tuscaloosa, AL 35487; USA; talamedalawson@ua.edu \\ 3 Department of Kinesiology, College of Education, University of Alabama, Tuscaloosa, AL 35487, USA; \\ karichards2@ua.edu \\ * Correspondence: malawson1@ua.edu; Tel.: +1-205-348-4807
}

Academic Editor: Hal A. Lawson

Received: 1 May 2016; Accepted: 7 June 2016; Published: 14 June 2016

\begin{abstract}
Community schools have recently (re)emerged in the United States as a vital, comprehensive strategy for addressing poverty-related barriers to children's school learning. However, not all low-income school communities are endowed with the resources needed to launch a comprehensive array of school-based/linked services and programs. In this article, the authors describe a place-based model for school improvement for low-income school communities where formal and fiscal resources are in short-supply. Framed by two best-practice interventions from the youth development and family support literatures, the authors identify five "high leverage" improvement mechanisms that social workers, educators, and parents can collaboratively target to affect change. These improvement mechanisms, together with the interventions they implicate, can help community school efforts provide a more powerful, engagement-focused reach into students' peer, family, and community ecologies.
\end{abstract}

Keywords: community schools; collective parent engagement; teaching personal and social responsibility; university-assisted community schools; community collaboration; interprofessional collaboration

\section{Introduction}

How should schools serving large numbers of low-income children go about engaging their parents? What out-of-school-time resources and supports are needed to support the social, educational, and learning needs of low-income children and the schools that serve them? How might educators, social workers, and parents work together to address poverty-related barriers to children's school learning and overall healthy development? How might they combat social isolation and exclusion dynamics at school and in the community?

This Special Issue on place-based partnerships and new school designs offers several complex and compelling models for addressing these important questions. These models range from well-established efforts to implement comprehensive and integrative school-based learning support programs in the United States [1] to more broad, ecologically-driven and systems-oriented efforts in the UK that connect the work of schools and community agencies to policy makers and other networked government arrangements [2]. 
These models are vital for the field because they provide a unique combination of theoretically sound, practice-driven, and policy-relevant insight into how schools might be re-designed and/or re-purposed to support the needs of all economically poor students and families. At the same time, the very comprehensiveness of these models pose special challenges for school communities that lack the resources needed to develop, launch, and sustain such broad-based systems of care. Indeed, for the most resource challenged school-communities in the United States and elsewhere, the question is not whether more comprehensive efforts and supports are needed, necessary, or desirable, because they are. Instead, the more immediate and pressing question is how to best leverage the efforts of the school's one social worker, the community's one child welfare officer or eligibility worker, and the neighborhood's one non-governmental family service agency in support of the hundreds (or even thousands) of vulnerable children and families living in the community?

The place-based and university-assisted school-community improvement model described in this article is an attempt to address this quandary of how to go about affecting systemic issues like poverty and concentrated disadvantage without the formal, institutional resources needed to do so. Our programmatic response to this paradoxical challenge is to engage social workers, educators, university students and faculty, as well as community parents in the co-design of activities aimed to enhance the peer, family, and community ecologies of elementary school students (grades K-6). We pursue this particular model and approach with due recognition that solving problems like poverty and its correlates requires much more than an isolated series of school-based programs and services; they demand a comprehensive and coordinated policy response [1,3]. However, until such time that policy supports and conditions present themselves throughout the United States and elsewhere, children, youth, families, schools, communities, and the professionals that serve them need a place to start.

Our intent in this article then is to map the theoretical and empirical warrants of a resource generative, place-based model for addressing the social, cultural, educational and developmental needs of low-income, elementary school-aged children and their families. In so doing, we hope to contribute to the on-going scholarly conversation about how to best tailor and "place" school-community initiatives in ways that support the needs of the most vulnerable children and families, living in the most vulnerable and challenging places.

Our discussion begins with a brief, theoretical rationale for our particular model and the accompanying improvement mechanisms that are targeted by it. Next, we introduce the primary components and resources associated with our effort to develop and implement a university-assisted, place-based model for enhancing students' peer, family, and community ecologies. From there, we introduce the methods and procedures used to promote the research, development, and dissemination of the effort. We conclude with select implications for policy makers, university-assisted community schools, as well as related school-community collaborations.

\section{Identifying Improvement Targets for School-Community Development}

For the past several decades, most educational research, policy, and practice in the United States has focused on improving student achievement by way of enhancing the school's instructional core [4]. In most low-income school communities in the United States, this strict emphasis on instructional improvement has been evident in the significant practice and policy investments schools and state departments of education have made in the following areas (see also [5]): (a) developing and implementing curricula that support college and career readiness; (b) enhancing school, teacher, and district capacity for data-driven decision making; and (c) administering rigid student testing and teacher accountability protocols.

Unfortunately, despite nearly 25 years of local, state, and federal investment in these improvement priorities and accountability structures, student achievement has largely not improved [6]. In fact, recent evidence suggests that student achievement in the United States has actually declined in tandem with the implementation of these policies. For instance, the most recent data from the 
National Assessment of Educational Progress (NAEP) indicates that 4th, 8th, and 12th graders in the United States have lost ground in math in the past two years, while reading scores have, in the main, declined since the early 1990's [7]. Moreover, while students at the top of the income distribution have experienced slight increases in academic achievement since the previous administration of NAEP in 2013, students in the bottom quartile of family income in the USA are faring significantly worse academically than they were just two years ago (ibid). The immediate implication that follows is that a focus on enhancing classroom instruction alone may be quite insufficient for improving educational outcomes for the majority of low-income children in the United States [8].

Of course, researchers have long documented the need for educational interventions to extend beyond the classroom and the school. This body of research has consistently shown that less than $15 \%$ of the variance in students' academic achievement outcomes are typically explained by school-related factors [9-11]. This curious and persistent finding highlights on-going needs for scholars to identify those malleable, extra school-related factors that carry the most consequence for enhancing students' educational outcomes.

\subsection{Applying the Pareto Principle to School-Community Improvement}

One of the more popular axioms from the economics literature is the Pareto Principle. This principle stipulates that $80 \%$ of the causes of a particular outcome typically stem from $20 \%$ of the factors. Although researchers have not formally applied the Pareto Principle's to the study of children's achievement outcomes, Pareto's axiom serves as an important planning heuristic for school communities that lack the resources needed to launch a comprehensive array of wrap-around programs and services. For these resource-limited places, the key planning directive is to identify a discrete number of theoretically sound, high-leverage practices or drivers (i.e., the 20\% of inputs) that, when properly activated, may stimulate outcome improvements for vulnerable children, youth, and families.

Our search for these high leverage intervention targets/drivers began by consulting the research literature as well as own prior experiences as practitioners and interventionists. Because our interest resided in identifying how children's school outcomes could be improved by extra-school forces, factors, and actors, our literature search proceeded with a social-ecological framework (i.e., [12]). This framework depicts students' engagement experiences and overall achievement trajectories as the complex result of interactions between and among their school, family, peer, and community ecologies.

Our review commenced with studies that enabled us to better understand the dynamics included within each of these ecological influences and settings (e.g., $[13,14])$. It concluded with research that afforded an understanding for how these settings might be positively synchronized/harmonized through intervention (e.g., [15]). Ultimately, our review of the research literature, coupled with our group dialogues, helped us identify five primary improvement mechanisms or drivers which helped frame our present work. These drivers were identified as salient for our particular model because they represent a potential set of high-leverage, malleable factors that can be impacted by place-based initiatives with limited fiscal resources. A graphic depiction of these factors and their presumed relationship to the development of children's school, peer, family, and community ecologies is provided for readers in Figure 1. 


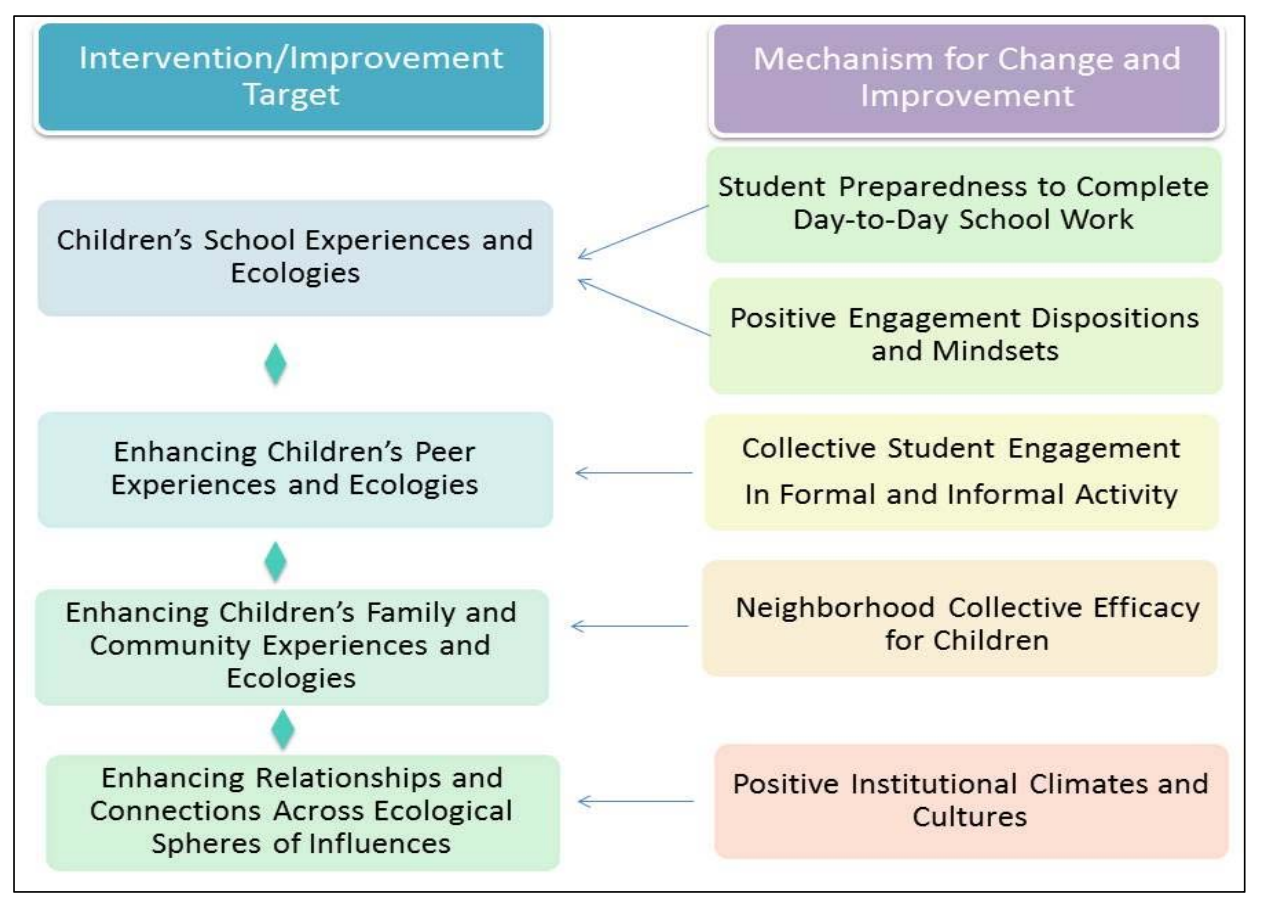

Figure 1. Hypothesized Mechanisms for Enhancing Students' School, Peer, Family, and Community Ecologies.

\subsection{Mapping Primary Improvement Drivers and Pathways}

As evident in Figure 1, the first improvement driver in our model centers on students' preparedness to complete their day-to-day work in the classroom. This driver was prioritized for the present work because research consistently identifies students' past-present academic standing as a leading predictor of their short- and long-term welfare in school [16]. In brief, because students who get behind tend to stay behind, finding culturally responsive ways to improve students' academic skills and competencies is a central priority for our work (e.g., [17]).

The second improvement driver encompasses students' perceptions of their social and academic competence, confidence, efficacy, and overall school-related identities [18]. Here, our work targets the development of two primary research-based concepts. The first such concept is a student engagement disposition, i.e., students' generalized orientation to engage (or not) in school and community life [19-21]. This engagement disposition concept is important for intervention planning because it encompasses students' sense of valuing and belonging toward school as well as their perceptions of the "will, skill, and thrill" they bring to academic studies and to the school environment overall (see also, [22]). Mirroring key aspects of self-determination theory [23], research indicates that students who develop "positive" engagement dispositions characterized by school valuing, competence, relatedness, and an overall enjoyment of school and academic work tend to have better grades, lower drop-out rates, and higher chances for enrollment in a four-year college or university [20].

One way that schools can help students develop positive dispositions is to target a second research-based concept. This concept is Carol Dweck's and David Yaeger's notion of mindsets. Students' academic mindsets are important for school-community improvement efforts because research shows that students' who view academic intelligence and/or ability as fixed (i.e., those that have "fixed mindsets") tend to fare significantly worse academically than students who believe that intelligence and ability are amenable to change (i.e., those that have "growth mindsets"; see [24]). Moreover, because student mindsets have been shown to be malleable to intervention, we view them as useful tools for helping students develop the academic dispositions they often need to complete high school and successfully pursue post-secondary careers [25]. 


\subsubsection{Extending the Lens of Improvement to Students' Peer, Family, and Community Ecologies}

The third primary driver in our model centers on students' peer group affiliations and the impact they have on children's academic achievement and social development. Peer groups represent an important action target in our model because research indicates that they often mediate the relationship between student engagement/motivation and children's academic outcomes [26]. What this finding means in practical terms is as follows: A student's individual motivations, dispositions, and mindsets will generally yield positive dividends for academic achievement only when their surrounding peer group has similarly positive views toward academics and school overall (see also, [27]). Accordingly, our model is designed to capitalize on the potential socializing power that might accompany the collective engagement of student peer groups [12].

The fourth primary driver targeted in our model centers on enhancing the quality of social relationships between low-income parents/families, schools, and other health and human service agencies in the community. This driver is targeted as a means of fostering a school-community climate and culture that can harmonize and synchronize children's school, peer, family, and community resources. Unfortunately, in many low-income school communities in the United States, the quality of these relationships is often poor [28-30], and these strained relationships have been shown to negatively impact the quality of children's school experiences, their educational aspirations, as well as their academic outcomes [31]. For all such reasons, finding ways to systematically break down social and cultural barriers between low-income families, schools, and other helping institutions is critical for supporting children's educational welfare and social development. Reducing these barriers-both real and perceived-is also critical for helping school and community parents learn how to best maximize the social, health, housing, and financial resources available in their community [32].

The fifth and final primary driver in our model centers on the development of place-based collective efficacy for children. Collective efficacy is an important social construct for improvement models like ours because it helps to account for positive child, parent, and social outcomes, including enhancements to children's health, improved cognitive functioning, decreased crime and delinquency, better birth outcomes, and improvements in school outcomes [33].

Essentially, collective efficacy refers to the extent to which community residents intervene on behalf of children's welfare [33]. Residential communities with high collective efficacy have special, important features. Above all, parents and other adults are observant and active. They notice what children do and do not do, and they take action when troubles arise at home, school, and in the community. They thus help to prevent undesirable outcomes at the same time they help create conditions for desirable ones.

In contrast, when place-based collective efficacy is low, parents and other adults may not be aware of children's needs and problems. Even if they are, they are not likely to take action. When this pattern prevails, educators, community health and social service professionals and others are on their own in their work with children and youth. Lacking the assistance, supports, and resources that parents and other adults provide, professionals' work is more challenging because children bring their learning and developmental barriers to school.

Framed in this way, the construct of social capital [34] represents an important heuristic for understanding and building collective efficacy. It refers to the resources embedded in social networks that allow people to gain access to needed social supports and resources (e.g., informational, financial, educational). Three indicators-as-measures of social capital help to explain place-based collective efficacy for children.

The first is shared norms for children, especially norms shared by parents, other local residents, educators, other professionals and civic leaders [34]. These shared norms are associated with the positive meaning of social control. Prosocial norms, widely shared and enforced, facilitate desirable social control because they help to prevent deviant, problematic behavior [33].

The second social capital feature is intergenerational closure [34], which refers to the extent to which parents know the parents of their children's friends and classmates [29]. Intergenerational 
closure is important aspect of social capital because, when activated, it facilitates parent-to-parent communications and family-to-family networks. Research suggests that when this kind of intergenerational closure is "high" in communities, parents regularly have the opportunity to observe their children in different situations, talk with other parents about their children's actions and behaviors, and share responsibility for the implementation of collective norms for how their children can and should behave at home, at school, and in the community.

The third indicator of a community's social capital for collective efficacy is reciprocated exchange, which refers to the quality of interactions that occur between individuals and their families. Whereas intergenerational closure refers to the extent to which parents and their children know each other by face or name, reciprocated exchange is used to evaluate whether these social relationships facilitate the exchange of needed social supports, assistance, and resources (e.g., material, information, and social; [33]).

This important idea of reciprocated exchange illuminates the distinction between structural social capital and functional social capital [35]. Structural social capital refers the quality and character of parent, family, and resident network ties. Functional social capital refers to the capacity of networks to provide its members with needed resources. Social capital resources in service of collective efficacy become functional when individuals (e.g., children, parents) and entire families draw on them. It is this transition-from structural to functional social capital - that we aimed to develop through our approach to place-based and university-assisted school-community improvement.

\section{Introducing the University-assisted, Place-based Model}

The TOPS model is a university-school-community partnership effort that has been developed between the authors' host university, a local elementary school and school district, and a neighborhood-based service agency bearing a similar name (i.e., Tuscaloosa's One Place). The effort is funded by a two-year seed grant of 75,000 US Dollars (per annum) that was awarded to the authors from their home university. The model was designed to serve elementary school children and their parents, with a particular eye toward fostering the development of the five primary improvement drivers identified in the previous section.

The school-community targeted by the effort is a low-income, predominately African American community that is challenged by high rates of unemployment as well as on-going social exclusion dynamics that follow a long history of racial segregation that remains largely in place today. In 2011, the community was largely decimated by a large tornado, which destroyed most of the housing and foliage in the community, as well as the elementary school targeted by the effort. The school re-opened two years ago and now serves nearly 450 students, $87 \%$ of which qualify for free or reduced lunch. Academically, the school ranks below the 30th percentile in student test scores in the state.

For the past several years, the school has partnered with a local, non-governmental family service agency named TOP (Tusacloosa's One Place) which receives money from the US Department of Education for afterschool programming, including required transportation (busing) from the school to children's homes. The TOP agency's staffing is limited, consisting of a handful of program coordinators who help buttress the agency's limited human resources by supervising social work interns drawn from the local university. Overall, the TOP agency represents the lone formal source of community-based support services in the community, as local and state taxes are not sufficient to support even a modest array of community-based health and human services programs.

Mindful of these fiscal constraints and the limitations they pose for the development and scale-up of the effort, the TOPS staffing structure was designed to leverage as many low-cost human resources as possible. Two resource development/allocation strategies were especially salient in this regard. First, we used our grant funding to provide matching funds for the school and the TOP agency so that they could invest in personnel who could supervise pre-service and in-service graduate and undergraduate students. Second, we worked with the degree coordinators from our university to ensure that student time and work on the project would count toward their respective degree and 
licensure requirements. The result of these efforts is that, each semester, the project serves as the primary work site for two master's level social work (MSW) interns (who each work 32 hours a week on the project) as well as 15 undergraduate pre-service physical education students that complete required early field experiences working on the effort. Moreover, as we detail in the following section, the work of the pre-service social workers and physical education teachers is buttressed by the work of community parents who are paid a weekly stipend for their participation in the effort. All in all, including supervision costs, our staffing and funding structure allows us to secure the part time services of nearly 25 people from the university, school, and neighborhood community for around 60,000 US dollars.

\subsection{Introducing the Model's Primary Interventions}

Although our staffing structure enables us to secure the resources of multiple pre-service and in-service professionals, our reliance on university students makes consistent staff turn-over an inescapable reality. In light of this challenge, we realized early in the planning process that, in order to reduce the cognitive load placed on staff and students, the program needed to be structured as simply as possible and within a limited range of interventions. We therefore narrowed our program design to focus on two particular "best practice" models that, when properly implemented, have the potential to successfully impact the five primary improvement drivers identified earlier in the paper.

The first such best practice model selected is a sport-based youth development model called Teaching Personal and Social Responsibility (TPSR; [36,37]) that we implemented to augment the school's existing efforts to support students in need of remediation. The second best practice model is a social work assisted family support and community development strategy called collective parent engagement (CPE; $[38,39])$. Both approaches target the development of students' peer, family, and community ecologies during out-of-school time. A brief description of each intervention follows.

\subsubsection{Teaching Personal and Social Responsibility}

The youth development component of the TOPS model is a school-based effort designed to support the engagement of about $20 \%$ of the elementary school's children. Students are referred to the program by the school's emergent leadership team based on the following criteria: (a) student risk of academic difficulty (i.e., being one grade level behind in reading); (b) student risk of behavioral difficulty (i.e., receiving an out-of-school suspension); and (c) student risk of truancy and attendance problems (i.e., student missed 3 or more days of school during any month of the school year). Students who experience multiple risks are given top priority for admission into this voluntary program.

The afterschool program runs for 90 minutes following the normal school day. As a part of the program design, students are divided equally (based on grade level) into two groups or cohorts. Each student group then takes turns participating in two 45-minute "blocks" of programmatic activity.

The first block of afterschool activity focuses on first improvement driver (i.e., student preparedness to complete their day-to-day academic work). This part of the program is facilitated by a school teacher who receives partial funding from the program's university seed grant. The efforts of this schoolteacher are further supplemented by students from the local university who volunteer as tutors with the TOP family service agency. Throughout this 45-minute block, students receive homework support individually and in peer groups from university tutors. Students in the most-need of academic support are provided with individualized academic support from the supervising teacher.

The second block of afterschool time includes activities that follow the TPSR approach. This component of the afterschool program is facilitated by pre-service physical education teachers who work under the tutelage of a grant-funded doctoral student from the authors' university. Consistent with the TPSR approach [36,40], all TOPS afterschool activities emphasize the development of five primary competences in project children: (1) Respect for self, others, and one's environment; (2) Participation, effort, and self-motivation; (3) Self-directed learning and goal setting; (4) Leadership, 
caring, and helping others; and (5) Transfer of the previous four goals into other areas of their life, including their families, their community, as well as the classroom [37].

In order to facilitate the development of these competencies, each TPSR lesson is structured to include the following points of emphasis [36]. The first involves relationship time. Here, the pre-service PE teachers engage students in informal dialogues that are designed to create affective attachments between and among students and teachers. Next, each student instructor initiates an awareness talk with students. These awareness talks allow students to understand how the personal and social responsibility focus will be integrated into the lesson. Following these dialogues, students engage in the daily lesson focus, which includes skill development and physical activity, with an intentional emphasis on building individual and collective responsibility toward work, life, and family pursuits. Toward the end of the lesson, the instructor leads a group debriefing session to discuss the day's lesson as it relates to skill development and responsibility, as well as how each skill learned might transfer to other contexts and settings. Then, before dismissal, students are provided a dedicated time for individualized reflection on how they might use the current lesson to help them achieve individual and collective goals.

Significantly, research on this TPSR approach supports its effectiveness in helping youth take leadership roles, set meaningful goals, and develop prosocial behavior [41,42]. Research also indicates that the competencies gained by children through TPSR may transfer to other areas of their lives, including school and community environments [43,44]. For instance, in a recent study, Hemphill and Richards [45] found that student engagement in an afterschool TPSR-based program was related to improvements in children's behavior in school and community settings as well as their academic performance.

\subsubsection{Collective Parent Engagement}

The second component of the TOPS model is CPE, a social work assisted approach to family support. This CPE approach has been developed and field-tested in low-income communities in Florida and California. Pilot research on these CPE efforts indicates that it can be successfully implemented and adapted to meet the needs of low-income communities with large populations of Latino immigrants as well as African American families [38,39,46].

This CPE approach is unique in that it proceeds beyond conventional "parent involvement" strategies that aim to recruit individual parents to volunteer in service of the school. In contrast, the goal of CPE is to recruit, train, and organize groups (or collectives) of parents to design and run programs that can support the economic, social, health, and educational needs of parents-not only at school—but also in the neighborhood community (see also, [30]). Recent research on CPE has linked the intervention to enhancements in some of the key improvement drivers targeted by the TOPS effort, including neighborhood collective efficacy, child well-being, as well as children's academic achievement $[38,39,47]$.

In the TOPS model, CPE is facilitated by two MSW interns who work $32 \mathrm{~h}$ a week at the school site. The work of these interns is further supplemented by a grant-funded adjunct field instructor who is trained by the article's second author. Together, these social workers work to engage parents in home, school, and neighborhood settings.

As a general rule, CPE includes three primary design phases [48]. The first design phase is the "individual parent engagement phase". It includes the following activities: (a) Door-to-door outreach to the homes of parents who have children engaged in the TPSR component of the project; (b) A collaborative decision-making/needs assessment process, called the Nominal Group Technique, that allows parents to individually and collectively identify and prioritize the barriers and constraints that limit the educational development and social welfare of children and families in the community; and (c) A 40-hour Outreach Training course that focuses on four standard modules (community outreach; communication; family assessment and family interviewing; and agency referral). 
The second design phase of CPE includes project activities that target the development of the parent collective. Throughout this "collective development" phase, project social workers provide parents with additional training and resources, including a weekly stipend for their on-going engagement and participation. These resources are provided so that parents may collectively design and implement programs that meet their own conceptions of the barriers/challenges that exist in their school and neighborhood community. This "user-centered" feature of the project is important as it allows the effort to be uniquely grounded or "placed" in each community in which it is implemented.

Examples of programs developed by parents in previous CPE efforts include: (a) a Referral and Information Network that helped parents complete paperwork and enrollment applications for local, state, and federal assistance programs; (b) a Home Visitation program that enabled CPE parents to take lead roles in solving solve public health issues like a school-wide Lice outbreak, as well as chronic truancy problems at school; (c) a Community Dollar Store run by parents that sold convenience items, health items (e.g., toothpaste, dish soap, laundry detergent), and (limited) fresh fruits and vegetables for a dollar per item, thereby reducing family needs to choose between food and health-related items; and (d) an Assets Exchange Program where parents provided training and services to other parents based on their own individual and family talents (see also [48]). Examples of the training and services provided from parents to others included cooking, hairstyling, household and budget management, sewing, cosmetology, as well as dance classes and fitness training.

The third design phase of CPE centers on the development of a school-community collaborative. This collaborative is intended to promote family access and use of neighborhood services and resources. When effectively implemented, past versions of these collaboratives have helped to facilitate significant shifts in service design and delivery [38,39,49].

One such shift is social service professionals' transition from a strict expert, solo service provider role to a more flexible, bottom-up, and collaborative approach that builds on family strengths and leverages parent guidance and leadership. When professionals engage with parents around their assessments about how services and resources can be re-arranged or re-allocated, important policy (and practice) changes and developments were documented at prior CPE intervention sites [38]. Examples of these developments have included the creation and ratification of a Client Bill of Rights for the treatment of low-income families in county agencies, the installation of traffic lights and crosswalks in the community that were dangerous for children, the provision of educational (English, Early Education), social (alcohol and drug), and health services at locations and times that were convenient for the community (often at the school), as well as the creation of a parent-run, not-for-profit agency and childcare center.

Important in their own right, when these policy-oriented efforts are combined with the informal supports and linkage mechanisms provided by parents, more sustainable and "anchoring" support systems are created in the community [50,51]. These anchoring supports are significant because they have been shown to create both social capital and collective efficacy in the community, including "vertical" bridging and linking relationships between families and social institutions, as well as important "horizontal" linkages between schools and health and human service agencies [38,39].

\section{Methods Used for Research and On-Going Improvement Planning}

The TOPS model was designed to be researched and developed by way of an iterative research methodology called Improvement Science [25]. Improvement Science is an analogue of the Design-Based Implementation Research (DBIR) movement of education and engineering [52], and the Community-Based Participatory Research (CBPR) approach of public health, social work, and education (e.g., [53,54]). Like CBPR, Improvement Science blurs traditional boundaries between researchers and their "research subjects" (i.e., research participants, clients, or community partners). These boundaries are blurred so that scholars can co-engage with practitioners and parents in the design and development of research that: (a) generates a more ecologically grounded view of the 
problems facing communities; and (b) helps communities gain insight into the helping practices that can help address their most pressing needs, problems, and challenges (see also [55,56]).

Framed in this way, Improvement Science allows researchers and practitioners to integrate research and evaluation directly into the overall design and delivery of community services. By integrating data collection and analysis activity directly into program development activity, helping professionals and community partners are provided with meaningful opportunities to develop the knowledge and wherewithal they need to improve their programs, practices, and services in "real time" [57]. As they learn to improve, the conditions for better helping practices and outcomes are created, together with a road map for achieving them reliably at scale.

\subsection{Primary Data Collection Activities and Procedures}

Consistent with the emergent methodology of Improvement Science, our data collection and analysis activities were designed to be integrated into the fabric of each program development activity sponsored by the effort. To assist with this continuous quality improvement effort, we developed a couple of basic planning tools. The first such tool, presented here as Table 1, helps explicate relations between the program's primary interventions, improvement targets, and relevant indicators/measures of program progress. The second tool, Figure 2, maps the effort's current "theory of improvement" by way of a planning/evaluation called a "driver diagram".

A driver diagram is a tool that allows improvement scientists to monitor the efficacy of their work relative to a particular outcome or aim. It is designed to reflect a process of "backward mapping". Each driver diagram begins with a brief statement about the desired outcome or aim targeted by the effort. This statement is typically featured on the far left of the diagram. The key change ideas (i.e., program services and inputs) then are typically presented on the far right hand side of the figure.

The key mediating mechanisms or "drivers" targeted by the effort are featured centrally in the middle of the diagram. This positioning reflects the working proposition that the relationship between a program's services and outcomes will prove positive if, and only if, the program's services can successfully impact its targeted drivers. As such, the underlying logic or theory embedded in a driver diagram flows unconventionally from right to left: The program's "key change ideas" are developed to activate the mechanisms (i.e., secondary drivers) that can impact the norms, structures or processes (i.e., primary drivers) that carry the greatest potential for enacting and exacting change [25].

Table 1. Map of Program Interventions, Activities, Drivers, and Measures.

\begin{tabular}{|c|c|c|c|}
\hline Intervention & Programmatic Activity & Targeted Drivers & Measures and Indictators \\
\hline \multirow{3}{*}{$\begin{array}{l}\text { Youth-Focused After } \\
\text { School Programming }\end{array}$} & $\begin{array}{l}\text { Academic Support } \\
\text { and Enrichment }\end{array}$ & $\begin{array}{l}\text { Student Preparedness to } \\
\text { Complete Academic Work }\end{array}$ & $\begin{array}{l}\text { Weekly Logs of Student Progress By } \\
\text { Classroom Teacher (i.e., Prepared, } \\
\text { Needs Support, Not Prepared) }\end{array}$ \\
\hline & \multirow{2}{*}{$\begin{array}{l}\text { Teaching Youth Personal } \\
\text { Responsibility (TPSR) }\end{array}$} & $\begin{array}{l}\text { Productive Student } \\
\text { Engagement Dispositions }\end{array}$ & $\begin{array}{l}\text { Behavioral and Emotional Rating Scale } \\
\text { (Improvement in Student Scores across } \\
\text { Sub-domains) }\end{array}$ \\
\hline & & $\begin{array}{l}\text { Positive and } \\
\text { School-Supportive Peer } \\
\text { Networks }\end{array}$ & $\begin{array}{l}\text { Behavioral and Emotional Rating Scale } \\
\text { (Improvement in Peer Group Scores } \\
\text { across Sub-Domains) }\end{array}$ \\
\hline \multirow{3}{*}{$\begin{array}{l}\text { Collective Parent } \\
\text { Engagement }\end{array}$} & Parent Training & $\begin{array}{l}\text { Positive and Productive } \\
\text { School Climate and Culture }\end{array}$ & Empowerment Outcomes Assessment \\
\hline & $\begin{array}{l}\text { Parent Guided and } \\
\text { Run Programs }\end{array}$ & Neighborhood Self Efficacy & Neighborhood Social Cohesion \\
\hline & $\begin{array}{l}\text { Community } \\
\text { Collaboration }\end{array}$ & $\begin{array}{l}\text { Neighborhood Self Efficacy } \\
\text { Positive School-Community } \\
\text { Climiate }\end{array}$ & $\begin{array}{l}\text { Modified Social Cohesion Scale for } \\
\text { School and Community Professionals }\end{array}$ \\
\hline
\end{tabular}




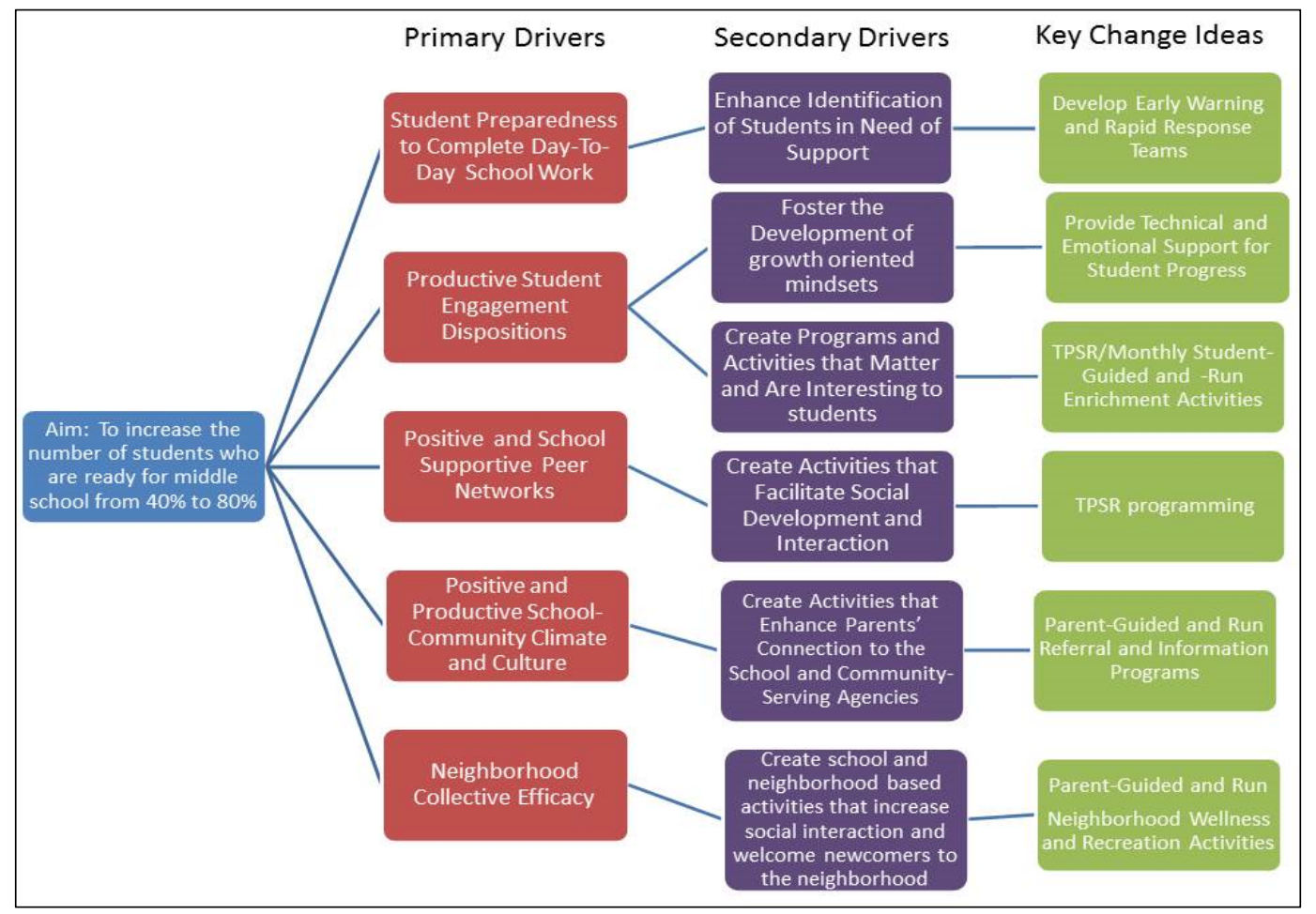

Figure 2. Driver Diagram of TOPS Model.

As depicted in our driver diagram, the primary aim of the TOPS effort is to increase the percent of students who leave elementary school with the social, psychological, and cognitive competencies/skills they need to successfully make the transition to middle school. Currently, the school's test scores indicate that about $40 \%$ of the student body is achieving this benchmark. Our aim is to increase this percentage to $80 \%$ over a five year period. Our theory is that by doubling the percentage of "middle school ready" students we can create the conditions for more enduring and successful learning experiences for students in middle school, high school, and beyond.

In order to provide a safeguard against test fatigue and to decrease the cognitive load placed on project staff and interns, our data collection plan is designed to be as unobtrusive as possible. For this reason, our analysis of our first primary improvement driver-student preparedness-is facilitated by the bi-weekly academic progress reports filed by school staff, namely the student's homeroom teacher. Our progress relative to the second and third improvement drivers is analyzed by way of survey data, namely the Behavioral and Emotional Rating Scale-2 (BERS-2).

The BERS-2 is a multi-modal assessment system with excellent psychometric properties [58]. It measures child behavior from three perspectives: the child (Youth Rating Scale), the parent (Parent Rating Scale), and the teacher (Teacher Rating Scale). The BERS-2 measures several aspects of a child's strengths, including their interpersonal strength (which aids in the understanding of how peer groups are being developed), involvement with family, intrapersonal strength, school functioning, affective strength, and career strength. In order to minimize the burden of continuous data collection on students, teachers, and the school overall, only parents and the TPSR student teacher who works with the student complete the BERS-2 scale each month. Each child and their homeroom teacher complete the scale four times a year (October, January, March, and May); we intentionally avoid administering surveys within two weeks of formal testing.

In order to monitor progress relative to the $\mathrm{CPE}$ component of the effort, we administer surveys to project and community parents up to three times during the academic year. We track progress relative to our fourth driver by administering the Empowerment Outcomes Assessment to CPE parents [59]. This 25-item survey captures parents' perceptions of their individual, interpersonal (group), 
and socio-political (e.g., their ability to access and influence community services) empowerment. We then monitor the development of social capital and collective efficacy in the community by administering the Perceived Neighborhood Social Cohesion Scale at school-community events [60] (which we also administer in a modified form to the school-community collaborative. This latter instrument utilizes a 7-point Likert scale to indicate the degree to which respondents endorse the following four items: "I really feel part of this area", "Most people in this area can be trusted", "If you were in trouble, there are lots of people in this area who would help you", and "Most people in this area are friendly".

Results from all aforementioned assessments are provided to parents (and school-community stakeholders) so that they can learn to evaluate the effectiveness of their own programs, including whether parents' programs sufficiently address the barriers they identify during assessment, and ultimately, whether they help to enhance desired outcomes at the school and in the community. When the data indicate needs to change or modify parents' programs and services, parents are supported by project social workers to modify and evaluate their own practices and strategies through the 90 day plan-do-study-act cycles highlighted in the Improvement Science research methodology [57]. In this way, data collection and analysis forms a feedback loop through which the current program structure is consistently evaluated, critiqued, and changed.

\section{Limitations and Conclusions}

This Special Issue of Education Sciences features developing exemplars for place-based partnerships and new school designs that address poverty, social exclusion, and social isolation. The TOPS model and approach described in this paper represents a "first generation" [31] place-based approach for marshalling school, family, community, and university resources in support of students' school, family, peer, and community ecologies (see also [50]). Our effort to create a resource-generative, place-based approach was purposeful because the effort resides in a US State that has a tax base and tax structure that inhibits the development of the kinds of comprehensive efforts featured in this Special Issue (e.g., [2]). As a consequence, in order to facilitate scale-up in similar school communities in our state, our pilot effort needed to be developed and launched with limited fiscal resources.

Although prior research and development on the model's two primary interventions provides optimism that we can achieve at least some of our aims, there are several important limitations associated with the effort that merit discussion. To begin, while the model is designed to impact key drivers of student and family experience in and around schools, there is no explicit mechanism in our program design that allows us to substantively alter what goes on inside classrooms during the school day. Consequently, while other models in this issue hold promise for facilitating the development of "new school designs", the effort described here might be best characterized as an approach that is best positioned simply to make existing school practices (and designs) work better.

A second key design limitation associated with our model relates to its scope of targeting only one elementary school and one neighborhood community. Although we have plans to extend the model to other parts of the school district in the months and years to come, students who "graduate" from the project's elementary school nonetheless portend to enter middle school without the same kinds of resources that have supported them previously. For this reason, vertically-directed community-school designs should be viewed as inherently superior to the more singular, stand-alone approach described in this article.

Despite these limitations, the TOPS model appears to offer university-assisted, school-community partnerships with a low-cost, theoretically sound, and place-based approach for addressing some of the key social-ecological barriers to student learning, engagement, and overall school success. In this respect, universities and professional schools can take stock of the alternative field placements created for pre-service teachers and social workers through this model, as well as the opportunities for inter-professional learning, training, and scale-up that accompany these alternative arrangements. Of course, all of these ideas stand merely as possibilities until such time that the effort is mature 
enough to undergo formal testing and evaluation. In the meantime, to the extent that this article helps to inform the development of similarly low-cost, university-assisted, place-based helping strategies, it will have achieved its primary purpose.

Acknowledgments: This article was supported by funding from the Research Grants Committee, Office for Sponsored Programs, the University of Alabama.

Author Contributions: All authors contributed equally to the research and writing of the paper.

Conflicts of Interest: The authors declare no conflict of interest.

\section{Abbreviations}

The following abbreviations were used in the manuscript:

CPE Collective Parent Engagement

TPSR Teaching Personal and Social Responsibility

\section{References}

1. Adelman, H.; Taylor, L. Immigrant children and youth in the USA: Facilitating equity of opportunity at school. Educ. Sci. 2016, 5, 323-344. [CrossRef]

2. Kerr, K.; Dyson, A. Networked social enterprises: A new model of community schooling for disadvantaged neighborhoods facing challenging times. Educ. Sci. 2016, in press.

3. Kerr, K.; Dyson, A. Developing an evidence-based rationale for a Children's Zone approach. Int. J. Res. Ext. Educ. 2014, 2, 97-112.

4. Adelman, H.; Taylor, L. The School Leader's Guide to Student Learning Support; Corwin: Thousand Oaks, CA, USA, 2005.

5. Darling-Hammond, L. The Flat World and Education: How America's Commitment to Equity Will Determine Our Future; Teachers College Press: New York, NY, USA, 2010.

6. Berliner, D.C. Poverty and Potential: Out-of-School Factors and School Success; The Great Lakes Center for Education Research and Practice: East Lansing, MI, USA, 2009. Available online: http://nepc.colorado.edu/ files/PB-Berliner-NON-SCHOOL.pdf (accessed on 5 May 2016).

7. Heiten, L. Low Performers Show Big Declines on 12th Grade NAEP Test. Education Week, 2016. Available online: http://blogs.edweek.org/edweek/curriculum/2016/04/12th_grade_naep_2015.html?cmp=eml-enleu-news1-RM (accessed on 24 May 2016).

8. Berliner, D.C. Our impoverished view of educational research. Teach. Coll. Rec. 2006, 108, 949-995. [CrossRef]

9. Coleman, J.S.; Campbell, C.J.; Hobson, J.; McPartland, A.M.; Mood, F.D.; Weinfeld, D.; York, R.L. Equality of Educational Opportunity; U.S. Government Printing Office: Washington, DC, USA, 1966.

10. Darling-Hammond, L. Can value added ad value to teacher education? Educ. Res. 2015, 44, 132-137. [CrossRef]

11. Hanushek, E.A.; Kain, J.; Rivkin, S. Teachers, Schools, and Academic Quality; National Bureau of Economic Research: Cambridge, MA, USA, 1998.

12. Lawson, M.A.; Lawson, H. New conceptual frameworks for student engagement research, policy, and practice. Rev. Educ. Res. 2013, 83, 432-479. [CrossRef]

13. Benson, P.; Scales, P.; Ruehlkepartain, E.C. A Fragile Foundation: The State of Developmental Assets among American Youth; The Search Institute: Minneapolis, MN, USA, 2011.

14. Lerner, R.M.; Lerner, J.; Almerigi, J.; Theokas, C.; Phelps, E.; Gestsdottir, S.; Naudeau, S.; Jelicic, H.; Alberts, A.; Ma, L.; et al. Positive youth development, participation in community youth development programs, and community contributions of fifth-grade adolescents: Findings from the first wave of the 4-h study of positive youth development. J. Early Adolesc. 2005, 25, 17-71. [CrossRef]

15. Eccles, J.S.; Roeser, R.W. Schools as Developmental Contexts during Adolescence. J. Res. Adolesc. 2011, 21, 225-241. [CrossRef]

16. Carneiro, P.; Heckman, J. Human Capital Policy. In Inequality in America; Friedman, B., Ed.; MIT Press: Cambridge, MA, USA, 2003. 
17. Hipkins, R. The engaging nature of teaching for competency development. In Handbook of Research on Student Engagement; Christenson, S.L., Reschly, A.L., Wylie, C., Eds.; Springer: New York, NY, USA, 2012; pp. 441-456.

18. Oyersman, D.; Johnson, E.; James, L. Seeing the destination, but not the path: Effects of socioeconomic disadvantage on school-focused possible self-content and linked behavioral strategies. Self and Identity 2011, 10, 474-492.

19. Crick, R.D.; Goldspink, C. Learner disposition, self-theories, and student engagement. Br. J. Educ. Stud. 2014, 62, 19-35. [CrossRef]

20. Lawson, M.A.; Masyn, K. Analyzing profiles, predictors, and consequences of student engagement dispositions. J. Sch. Psychol. 2015, 53, 63-86. [CrossRef] [PubMed]

21. Lawson, M.A.; Masyn, K. Analyzing profiles and predictors of students' social-ecological engagement. AERA Open 2015, 1, 1-37. [CrossRef]

22. Goldin, G.A.; Epstein, Y.M.; Shorr, R.Y.; Warner, L.B. Beliefs and engagement structures: Behind the affective dimension of mathematical learning. Math. Educ. 2011, 43, 547-560. [CrossRef]

23. Reeve, J. A self-determination theory perspective on student engagement. In Handbook of Research on Student Engagement; Christenson, S.L., Reschly, A.L., Wylie, C., Eds.; Springer: New York, NY, USA, 2012; pp. 149-172.

24. Yaeger, D.S.; Dweck, C.S. Mindsets that promote resilience: When students believe that personal characteristics can be developed. Educ. Psychol. 2012, 47, 302-314. [CrossRef]

25. Bryk, A.; Gomez, L.; Grunow, A.; LeMahieu, P. Learning to Improve: How American's Schools Can Get Better at Getting Better; Harvard University Press: Cambridge, MA, USA, 2005.

26. Fredericks, J.A.; Eccles, J.S. Is extra-curricular participation associated with developmental outcomes: Concurrent and longitudinal relations? Dev. Psychol. 2006, 42, 698-713. [CrossRef] [PubMed]

27. Horvat, E.M.; Lewis, K. Reassessing the "burden of acting White": The importance of Black peer groups in managing academic success. Sociol. Educ. 2003, 76, 265-280. [CrossRef]

28. Schutz, A. Home is a prison in the global city: The tragic failure of school-based community engagement strategies. Rev. Educ. Res. 2006, 76, 691-743. [CrossRef]

29. Horvat, E.M.; Weinenger, E.; Lareau, A. From social ties to social capital: Class differences in the relation between schools and parent networks. Am. Educ. Res. J. 2003, 40, 319-351. [CrossRef]

30. Warren, M.; Hong, S.; Rubin, C.; Uy, P. Beyond the bake sale: A community-based relational approach to parent engagement in schools. Teach. Coll. Rec. 2009, 111, 2209-2254.

31. Lawson, H.A.; Van Veen, D. Introduction. In Developing Community Schools, Community Learning Centers, Extended-Service Schools and Multi-Service Schools: International Exemplars for Practice, Policy and Research; Lawson, H.A., van Veen, D., Eds.; Springer International: The Hague, The Netherlands, 2016; pp. 1-19.

32. Bess, K.D.; Doykos, B. Tied together: Building relational well-being and reducing social isolation through place-based parent education. J. Community Psychol. 2014, 42, 269-294. [CrossRef]

33. Sampson, R.J. Great American City: Chicago and the Enduring Neighborhood Effect; University of Chicago Press: Chicago, IL, USA, 2012.

34. Coleman, J.S. Social capital in the creation of human capital. Am. J. Sociol. 1988, 94, S95-S120. [CrossRef]

35. Ishimaru, A. When new relationships meet old narratives: The journey towards improving parent-school relations in a district-community organizing collaboration. Teach. Coll. Rec. 2014, 116, 49.

36. Hellison, D. Teaching Responsibility through Physical Activity; Human Kinetics: Champaign, IL, USA, 2011.

37. Gordon, B.; Doyle, S. Teaching personal and social responsibility and transfer of learning: Opportunities and challenges for teachers and coaches. J. Teach. Phys. Educ. 2015, 34, 152-161. [CrossRef]

38. Alameda-Lawson, T.; Lawson, M.A. Ecologies of collective parent engagement in urban education. Urban Educ. Adv. Online Publ. 2016. [CrossRef]

39. Lawson, M.A.; Alameda-Lawson, T. A case study of school-linked, collective parent engagement. Am. Educ. Res. J. 2012, 49, 651-684. [CrossRef]

40. Weiss, M.; Wiese-Bjornstal, D.M. Promoting positive youth development through physical activity. President's Counc. Phys. Fit. Sports Res. Digest 2009, 10, 1-8.

41. Gordon, B. An examination of the responsibility model in a New Zealand secondary school physical education program. J. Teach. Phys. Educ. 2010, 27, 138-154.

42. Wright, P.M.; Burton, S. Implementation and outcomes of a responsibility-based physical activity program integrated into an intact high school physical education class. J. Teach. Phys. Educ. 2008, 27, 138-154. 
43. Walsh, D.; Ozaeta, J.; Wright, P.M. Transference of responsibility model goals to the school: Exploring the impact of a coaching club program. Phys. Educ. Sport Pedagog. 2010, 15, 15-28. [CrossRef]

44. Wright, P.M.; Li, W.; Ding, S.; Pickering, M. Integrating a personal and social responsibility program into a wellness course for urban high school students: Assessing implementation and educational outcomes. Sport Educ. Soc. 2010, 15, 277-298. [CrossRef]

45. Hemphill, M.A.; Richards, K.A.R. “Without the academic part, it wouldn't be squash": Youth development in an urban squash program. J. Teach. Phys. Educ. 2016, in press.

46. Alameda-Lawson, T.; Lawson, M.A.; Lawson, H. Social workers' roles in facilitating the collective involvement of low-income, culturally diverse parents in an elementary school. Child. Sch. 2010, 32, 172-182. [CrossRef]

47. Alameda-Lawson, T. A pilot study of collective parent engagement and children's academic achievement. Child. Sch. 2014, 36, 199-209. [CrossRef]

48. Alameda-Lawson, T.; Lawson, M.A.; Lawson, H. An innovative collective parent engagement model for families and neighborhoods in arrival cities. J. Fam. Strengths 2013, 13, 1-24.

49. Alameda-Lawson, T.; Lawson, M.A. Building Community Collaboratives. In Pathways to Power: Readings in Contextual Social Work Practice; O’Melia, M., Miley, K., Eds.; Allyn \& Bacon: Boston, MA, USA, 2002; pp. 108-128.

50. Netter Center for Community Partnerships. Anchor Institutions Toolkit: A Guide to Neighborhood Revitalization; Netter Center, University of Pennsylvania: Philadelphia, PA, USA, 2008.

51. Warren, M. Communities and schools: A new view of urban education reform. Harv. Educ. Rev. 2005, 75, 133-173. [CrossRef]

52. Fishman, B.J.; Penuel, W.R.; Allen, A.-R.; Cheng, B.H.; Sabelli, N. Design-based implementation research: An emerging model for transforming the relationship of research and practice. Des. Based Implement. Res. 2013, 112, 136-156.

53. Israel, B.A.; Schulz, A.J.; Parker, E.A.; Becker, A.B. Review of community-based participatory research: Assessing partnership approaches to improve public health. Ann. Rev. Public Health 1998, 19, 173-202. [CrossRef] [PubMed]

54. Jurkowski, J.; Mills, L.; Lawson, H.; Bovenzi, M.; Quartimon, R.; Davison, K. Engaging low-income parents in child obesity prevention from start to finish: A case study. J. Community Health 2013, 38, 1-11. [CrossRef] [PubMed]

55. Coburn, C.E.; Penuel, W.R. Research-practice partnerships in education: Outcomes, dynamics, and open questions. Educ. Res. 2016, 45, 48-54. [CrossRef]

56. Wandersman, A. Four keys to success (theory, implementation, evaluation, resource/system support): High hopes and challenges in participation. Am. J. Community Psychol. 2009, 43, 3-21. [CrossRef] [PubMed]

57. Lewis, C. What is improvement science? Do we need it in education? Educ. Res. 2015, 44, 54-61. [CrossRef]

58. Buckley, J.; Epstein, M. The behavioral and emotional rating scale-2 (BERS-2): Providing a comprehensive approach to strengths-based assessment. Calif. Sch. Psychol. 2004, 9, 21-27. [CrossRef]

59. Parsons, R.J. Assessing helping processes and client outcomes in empowerment practice: Amplifying client voice and satisfying funding sources. In Empowerment Practice in Social Work: Developing Richer Conceptual Foundations; Shera, W., Wells, L.M., Eds.; Canadian Scholars' Press, Inc.: Toronto, ON, Canada, 1999.

60. Kim, E.; Park, N.; Peterson, C. Perceived neighborhood social cohesion and stroke. Soc. Sci. Med. 2013, 97, 49-55. [CrossRef] [PubMed]

(C) 2016 by the authors; licensee MDPI, Basel, Switzerland. This article is an open access article distributed under the terms and conditions of the Creative Commons Attribution (CC-BY) license (http:/ / creativecommons.org/licenses/by/4.0/). 